\title{
Applying Serious Games in Lean Manufacturing Training
}

\author{
M. Messaadia ${ }^{1}$, A. Bufardi ${ }^{2}$, J. Le Duigou ${ }^{1}$, H. Szigeti ${ }^{3}$, B. Eynard ${ }^{1}$, and D. Kiritsis ${ }^{2}$ \\ ${ }^{1}$ Université de Technologie de Compiègne, \\ Department of Mechanical Systems Engineering, CNRS UMR6253 Roberval \\ BP 60319, rue du Docteur Schweitzer, 60203 Compiègne Cedex, France \\ \{mourad.messaadia, julien. le-duigou, benoit. eynard\} @utc. fr \\ ${ }^{2}$ Ecole plytechnique Fédérale de Lausane (EPFL), Switzerland \\ \{ahmed.bufardi, dimitris.kiritsis\}@epfl.ch \\ ${ }^{3}$ DELMIA Dassault Systèmes, 10 Rue Marcel Dassault - 78946 Velizy Villacoublay, France \\ hadrien.szigeti@3ds.com
}

\begin{abstract}
In this paper, we report on the outcomes of one of the most successful training events organized within the framework of ActionPlanT project. This event was planned using the bottom-up approach of the ActionPlanT Industrial Learning model. The "Muscle car" serious game was used to deliver the training content about lean manufacturing to the participants in this event. The feedback received from the participants through the completed questionnaires indicated that serious games are suitable delivery mechanisms for training themes such as Lean Manufacturing.
\end{abstract}

Keywords: ActionPlanT IL model, serious games, Lean manufacturing, ILPE.

\section{Introduction}

Among the challenges of industrial learning (IL) is the inadequacy of learning content and delivery mechanisms to the new learning requirements of the manufacturing workforce.

ActionPlanT project produced a baseline document providing recommendations about instruments, methodologies and activities to deliver effective IL programs for the future e-skills in manufacturing. Among these recommendations is the use of tailored delivery mechanisms for the training of manufacturing workers that take into account their specific needs and constraints.

This paper reports on the outcomes of a training event organized within the framework of ActionPlanT project where a game-based learning mechanism is used to deliver training content to employees from an electronics manufacturing industry.

One of the main activities of ActionPlanT project is the development and validation of a concept for IL, extensively piloted via Industrial Learning Pilot Events (ILPEs) and workshops amongst stakeholders in industry, academia, and the European technology platforms alike. 
In ActionPlanT project, an IL model and methodology were developed [1]. Their implementation is executed through the organization of a series of ILPEs where promising delivery mechanisms and manufacturing themes are tested and evaluated for selected target groups. ILPEs are considered as instances of the comprehensive ActionPlanT IL model.

The ActionPlanT IL model is competence-based and is suitable for creating new knowledge assets related to "cutting edge" information and communication technologies (ICTs) for manufacturing, identifying corresponding new professional competencies, and defining relevant learning programs and actions to train workers and engineers to develop these competencies.

The ActionPlanT IL methodology aims at implementing through a number of steps the IL actions defined using the ActionPlanT IL model for a specific learning situation. This includes the identification of the target group and their learning needs, and the choice of adequate delivery mechanisms and appropriate evaluation tools.

The organisation of an ILPE involves 4 main components: the delivery mechanism, the learning theme, the target group, and the training process which encloses the set of activities required to allow delivering the training theme to the target group using the delivery mechanism.

The second section describes the serious game deployment for lean manufacturing training. Third section describes results of applying different types of organization, the evolution from one round to another one and the ILPE evaluation. Finally, the conclusion and future perspectives for ILPE and the evolution of the serious game deployed.

\section{The ILPE Applying Serious Game in Lean Manufacturing Training}

The role of learning for capacity building is seen as paramount for industrial development and enhancing added value. The factors behind the successful industrial learning have not been appropriately conceptualized in the existing academic literature [2]. The ILPE applying serious game in lean manufacturing training will be an evaluation of the industrial learning. The ILPE applying serious game in lean manufacturing training will be an evaluation of the industrial learning, and a way to deepen the theoretical and practical understanding of Industrial learning implementation.

\subsection{Description of the ILPE and Its Objectives}

For the ILPE reported in this paper, we used the bottom-up approach of the ActionPlanT IL model and identified the "application of lean principles" as a professional need for the community (target audience) of employees from an electronics manufacturing industry which guided us to define the appropriate training content that we delivered using a game-based learning mechanism.

One of the main strengths of serious games is their ability to provide job like training environments which is very appreciated by trainees from manufacturing industry. 
The main objectives of this ILPE were to test and evaluate the following aspects:

1. the learning process building blocks for competence development in Lean Manufacturing: knowledge, skills, and attitude,

2. the serious game delivery mechanism,

3. team work (collaboration, communication, conflict resolution, group decision making, etc.) of the participants within each team.

This one-day training event was organized for 19 participants from the same company but having different responsibilities.

The serious game exercise was followed by a more formal presentation on Lean principles and the kind of ICT systems that are needed to implement them in modern production organizations. The objectives of the presentation were twofold: (i) to explain to the participants the lean principles they applied in the exercise and (ii) to emphasize the importance of ICT to improve the implementation of Lean principles.

\subsection{The "Muscle Car" Serious Game}

Lean manufacturing can be defined as a business system and a generic process management philosophy with a systematic approach to eliminating waste through continuous improvement [3]. Lean manufacturing and its key principles take their origins from Toyota Production System (TPS) more generally known as lean manufacturing.

The game selected for this ILPE is the "Muscle Car" serious game; it's based on the Lean manufacturing concepts. The purpose of this game is the simulation of car's assembly line. The objective is to assemble as many cars as possible while at the same time keeping the inventory cost as low as possible.

By playing Muscle Car, the participants are expected to face problems and constraints of manufacturing industry that will need to be fixed using different solutions.

The game is based on LEGO ${ }^{\circledR}$ car models where the participants are divided into teams, and compete during 3 rounds of 3 simulated weeks of 5 days. Short breaks simulating the weekends are also considered in the exercise.

Muscle Car is the delivery mechanism used in this ILPE.

\subsection{Running the Game}

The participants in this event were partitioned into two teams. Each participant played a specific role in his team (Autonomous Production Unit (APU) manager, transporter, Final Assembly Line manager, etc.).

In this ILPE, 3 different types of organization were applied and evaluated: traditional, self optimized and lean. The game was run in 3 rounds (a round for each type of organisation) and at the end of each round, the performance of each team was shown to both teams.

Regarding the traditional organization applied in the first round of the game, the participants produced cars according to a specific organization described by the game rules provided by the instructors during the introduction of the ILPE. 
Regarding the self optimized organization, the participants of the two teams proposed their own organization in order to fix the different problems and constraints they encountered in the first round of the game where the traditional organization was applied. In each team, the participants collaboratively defined the type of organisation to adopt and collectively agreed on it.

Regarding the lean organization, the participants put some Lean principles provided by the instructors into practice in order to make the production more efficient. It was assumed that the new lean organisation is suggested by a consulting firm specialized in Lean manufacturing. In this new organisation all APUs were reorganized into "Pull Flows": an APU could only produce if there was a demand from its "internal customer", i.e. the APU that consumes its sub-systems.

The game was significantly improved through the introduction of the intermediate round (which does not exist in the original version of the game) where the participants proposed their own organization (self optimized) in order to fix the problems encountered in the first round. The intermediate round allowed the participants to better follow and understand the evolution from a traditional organization to a lean organization and showed that the adoption of lean principles is a normal tendency in a group in the case of organization problems. This was appreciated by both the trainees and the expert trainers.

\subsection{Muscle Car versus Lean Manufacturing Concepts}

There are many tangible benefits associated with lean Manufacturing, such as the automotive industry. Among these benefits we have decreased lead times for customers; reduced inventories for manufacturers; improved knowledge management; more robust processes (as measured by less errors and therefore less rework) [4].

Muscle car is not just a game, but it is the implementation of lean manufacturing concepts through practice and simulation. It's a stimulating and effective teaching tool through participatory and collaborative activities. It strengthens the social dimension and interactions, and ensures the participation and motivates the audience. The serious game is not intended to apply all lean manufacturing concepts, but rather to discuss some concepts in practice.

Among Lean Manufacturing concepts used in this game we find:

- Standardization: concentrates on standardizing best practice in each work area. The game consists to produce two different types of cars with different structure and color. However, we considered standard modules to both types of cars, such as engine, wheels etc. We also establish precise procedures for each APU's work through precise work sequence.

- Kaizen (Continuous improvement): describes an environment where companies and individuals proactively work to improve the manufacturing process. The concept is introduced by the integration of the $2^{\text {nd }}$ round where everybody interacts and exchange, and submit his proposition.

- Kanban: a visual signal to support flow by 'pulling' product through the manufacturing process as required by the customer. In the game Kanban is seen 

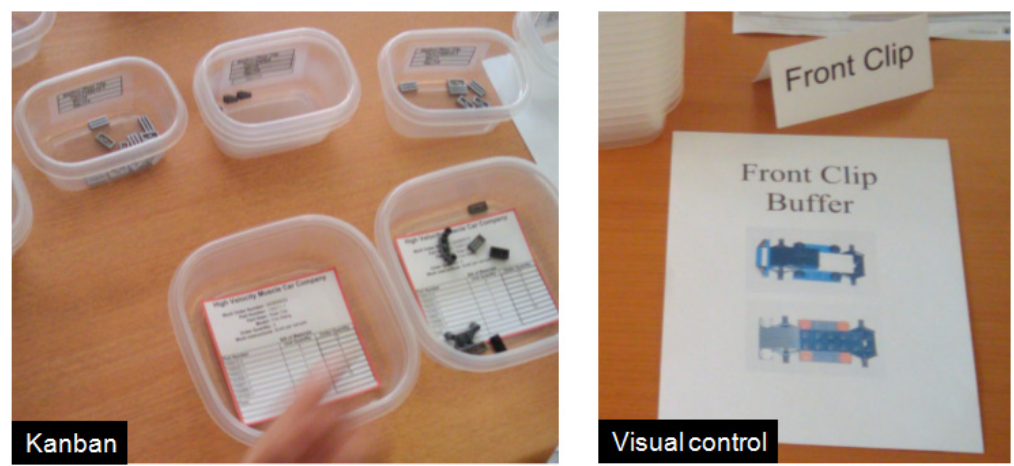

Fig. 1. Lean manufacturing concepts illustration

through different APU's of sub-assembly components. APU contains small/large bins for component/module storage (Fig.1). Each bin has a unique label designating the reference, quantity of component, etc.

- Visual control: a method of measuring performance at the 'shop floor' which was visual and owned by the operator team. The concept is introduced progressively, through procedures, the identification of different APU, the transparency of the bins (On each APU it is possible to know the risk of missing components). We introduce in the $3^{\text {rd }}$ round Buffers which represent the identification of storage areas (Fig.1).

\section{$3 \quad$ Results and Evaluation}

The efficiency of each given type of organization was measured using two types of criteria: (i) the number of cars produced (which should be maximized) and (ii) the inventory cost (which should be minimized).

The results of the exercise (number of assembled cars and the inventory cost) are compared in two different ways: (i) for each team according to the different types of organization to see how they are performing with respect to the number of cars produced and the inventory cost, and (ii) between the two teams for each type of organization where the objective is to check whether similar trends are observed within the two teams.

At the end of the serious game we make debrief of the 3 rounds in order to discuss various rounds and especially to show profits of lean manufacturing. Teams will be able to see their mistakes and see for themselves the results.

(Fig. 2) shows inventories obtained during the serious game and presented to players at the end. Three different colors to distinguish different rounds:

- Blue (Traditional factory): first round, where traditional organization was proposed;

- Red (Optimized factory): second round, where teams organize themselves; 
- Green (Lean Factory): third round, where the lean manufacturing solution was proposed.

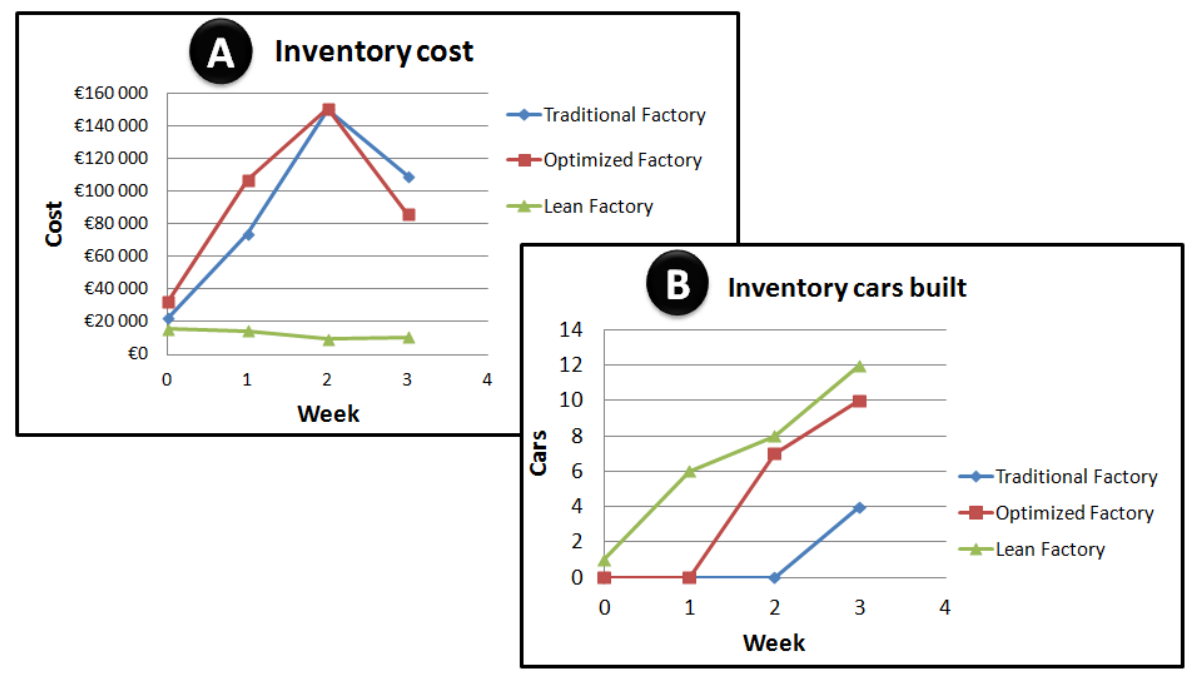

Fig. 2. Comparison of "Muscle Car" rounds

(A) Inventory cost: during 3 workweeks each APU will produce parts of car until the final assembly. Every weekend, we made an inventory of parts produced by APU's and don't assembled on the cars. This represents goods in progress and storage costs. For this we assigned a cost to each part.

(B) Inventory cars built: during the game, the goal of participants is to build maximum cars in line with customer's requests. Every weekend, we made an inventory of cars built.

As a result of applying the tree different types of organization, the lean factory organization had the highest number of assembled cars and the lowest inventory cost among the three types of organization for the two teams which means that lean organisation dominates the two other types of organisation since it performs better than them on both criteria.

Another aspect according to these organization and we don't see it through the figure is the working atmosphere. In the first and second rounds participants were working under pressure and moved in all directions. Often they cried out for the part. During the last round, despite the competitive spirit was always present, participants were calmer and focused on their work and did not need to shout.

For the evaluation of the ILPE, a questionnaire was distributed to all the participants during the training session and has been filled-in right after the end of the event. The questionnaire has been structured around the four major building blocks of the learning process (Table 1), which are addressed by the ActionPlanT IL model/methodology, i.e. attitude, knowledge, skills, and competencies [5]. 
Table 1. 4th ActionPlanT ILPE goals regarding attitude, knowledge skills and competencies

\begin{tabular}{|c|c|c|}
\hline & Definition & $4^{\text {th }}$ ILPE Goals \\
\hline Attitude & $\begin{array}{l}\text { "Attitude" is a hypothetical } \\
\text { construct that represents an } \\
\text { individual's degree of like or } \\
\text { dislike for an item. Attitudes are } \\
\text { generally positive or negative } \\
\text { views of a person, place, thing, } \\
\text { or event. }\end{array}$ & $\begin{array}{l}\text { Create awareness and attract } \\
\text { interest with respect to Lean } \\
\text { Manufacturing and the supporting } \\
\text { ICTs }\end{array}$ \\
\hline Knowledge & $\begin{array}{l}\text { "Knowledge" means the } \\
\text { outcome of the assimilation of } \\
\text { information through learning. } \\
\text { Knowledge is the body of facts, } \\
\text { principles, theories and practices } \\
\text { that is related to a field of work } \\
\text { or study. }\end{array}$ & $\begin{array}{l}\text { Create a basic understanding about } \\
\text { the major principles, pillars and } \\
\text { limitations of Lean Manufacturing, } \\
\text { as well as about the manufacturing } \\
\text { ICTs (e.g. MES, ERP, RFID etc.) } \\
\text { implementing the underlying } \\
\text { principles and enabling lean } \\
\text { production }\end{array}$ \\
\hline Skills & $\begin{array}{l}\text { "Skills" means the ability to } \\
\text { apply knowledge and use know- } \\
\text { how to complete well defined } \\
\text { tasks. Skills may be cognitive or } \\
\text { practical }\end{array}$ & $\begin{array}{l}\text { Apply different schemes for team } \\
\text { work organization and information } \\
\text { processing in assembly operations, } \\
\text { including traditional schemes, self- } \\
\text { organization and lean principles }\end{array}$ \\
\hline Competencies & $\begin{array}{l}\text { "Competence" means the } \\
\text { proven ability to use knowledge, } \\
\text { skills and personal, social and/or } \\
\text { methodological abilities. } \\
\text { Competences may be } \\
\text { considered as the interface } \\
\text { between the learning and the } \\
\text { innovation processes. }\end{array}$ & $\begin{array}{l}\text { Develop the capability of } \\
\text { addressing realistic use cases } \\
\text { involved in car assembly } \\
\text { operations, requiring decision } \\
\text { making and optimization of } \\
\text { teamwork organization and } \\
\text { information processing }\end{array}$ \\
\hline
\end{tabular}

Based on the feedback received from the participants through the completed questionnaires, it was indicated that the "Muscle Car" serious game is a relevant delivery mechanism to learn lean principles and contributes to improve attitude, knowledge, skills and competencies about lean manufacturing.

\section{Conclusion}

Through the discussions between the participants and the instructors after the exercise, it seemed that the participants reached a good understanding of lean manufacturing and showed interest to learn further about it. 
The funny side of the game and the competition aspect between the two teams highly influenced the motivation and involvement of the participants in the exercise.

The addition of the intermediate round (self optimized organisation) was very much appreciated by the participants and illustrated the normal transition from traditional organisation to a lean organisation in order to solve organisational problems in a company.

This ILPE showed the great potential of serious games to deliver training content for workers in manufacturing companies. The serious game allows the trainees to learn in a job-like environment.

This kind of training events allows evaluating the compatibility of emerging delivery mechanisms with various training themes in manufacturing industry.

The ActionPlanT IL model and methodology provide efficient tools to organise IL actions for selected target groups.

As perspectives, we envisage the integration of a fourth round, based on ICT integration. This means the establishment of a simplified management information system. Also, ICT allows making information immediately visible to all, through electronic dashboard.

Acknowledgements. The research leading to these results has received funding from the European Community's Seventh Framework Programme (FP7/2007-2013) under grant agreement $\mathrm{n}^{\circ} 258617$.

The work in the ActionPlanT project is a common effort among all its contributing partners: Agoria, EPFL, Fraunhofer IPK, Dassault Systèmes, POLIMI, SAP, Tecnalia, University of Patras, and Platte Consult.

\section{References}

1. Kiritsis, D., Bufardi, A., Mavrikios, D., Knothe, T., Szigeti, H., Majumdar, A.: A competence-based industrial learning approach for factories of the future: A result of the FP7-FoF project ActionPlanT. In: Proceedings of the 4th the International Conference on Computer Supported Education, Porto, Portugal, April 16-18 (2012)

2. Puidokas, M., Jucevicius, G.: The Inter-Organizational Industrial Learning of Lithuanian Furniture Manufacturers in the Value Chains of the Baltic Sea Region. Social Sciences Nr.3(65) (2009) ISSN 1392-0758

3. Womack, J.P., Jones, D.T.: Lean Thinking: Banish Waste and Create Wealth in Your Corporation. Simon \& Schuster, New York (1996)

4. Meleton, T.: The Benefits of Lean Manufacturing: What Lean Thinking has to Offer the Process Industries. Trans IChemE, Part A, Chemical Engineering Research and Design 83(A6), 662-673 (2005)

5. Mavrikios, D., Papakostas, N., Mourtzis, D., Chryssolouris, G.: On industrial learning \& training for the Factories of the Future: A conceptual, cognitive \& technology framework. Journal of Intelligent Manufacturing, Special Issue on Engineering Education (2011), doi:10.1007/s10845-011-0590-9 